\title{
Internet of things based attendance system design and development in a smart classroom
}

\author{
Dania Eridani, Eko Didik Widianto, Ike Pertiwi Windasari, Wildan Budi Bawono, \\ Nadia Febrianita Gunarto \\ Department of Computer Engineering, Diponegoro University, Semarang, Indonesia
}

\begin{tabular}{l}
\hline \hline Article Info \\
\hline Article history: \\
Received Oct 25, 2020 \\
Revised Aug 4, 2021 \\
Accepted Aug 10, 2021 \\
\hline
\end{tabular}

Keywords:

Attendance system

Classroom security

Classroom management

Fingerprint

Smart classroom

\begin{abstract}
Attendance records are one of the main administrative roles on campuses. Therefore, several technologies can be used on an attendance system, including barcode, radio frequency identification (RFID), fingerprint, and faceprint. The main functions of attendance systems on campuses are mainly focused on how to obtain the attendee data list, store on the database, and display the list on the information system. This research proposes an attendance system in the smart classroom which supports the system's previous activities as well as its integration with security and classroom management. In this system, the NodeMCU which was connected to the Wi$\mathrm{Fi}$ router served as the controller, while the fingerspot revo FF-153BNC functioned as the system input. In addition, the database server was used to allocate attendee and classroom management data. This system is connected with the information system and classroom display unit, and component and system testing were applied in this research. The results showed that each system unit successfully integrated and managed the attendance, security, and classroom schedule.
\end{abstract}

This is an open access article under the CC BY-SA license.

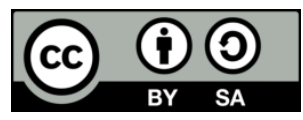

\section{Corresponding Author:}

Eko Didik Widianto

Department of Computer Engineering

Diponegoro University

Prof. H. Soedharto, Semarang, Indonesia

Email: didik@live.undip.ac.id

\section{INTRODUCTION}

Attendance records constitute one of the main administrative activities in every place such as office, campus, and school. These records are a tool to check whether a person attends an event or a business. Furthermore, it is not only used to identify an individual's presence, but can further analyze an event's problem [1], analyze teacher performance and impact in a classroom [2], [3], student behavior toward given parameters [4], [5], and check the readiness of people in facing technology [6].

Therefore, an attendance system was built to accomplish the uses of attendance. There are various technologies used to create or develop this system, such as RFID. The RFID represents a unique ID of a person or object, and its tag can be used to identify an individual's presence [7]-[10] in an event or place by scanning through the RFID reader. Furthermore, it is possible to build this system through a biometric process that uses fingerprint and facial recognition. In some research [11]-[17], the fingerprint is used to build an attendance system. Aside from fingerprint, facial recognition technology can be implemented to scan an individual's presence [18], or can effectively scan multiple faces on one screen[19]. It is also possible to combine several technologies to build this system [20]-[23]. Factually, its main purpose involves the use of technology to verify someone's presence and manage it on an information system or a mobile-based application. 
At campuses, one of the attendance processes is performed in a classroom, where lectures and students undergo this process to record their presence. Nowadays, the classroom itself is optimized with several technologies. Smart classrooms are built to have automation over objects inside the classroom, such as lighting, air conditioner, and projector. [24]-[26]. There have also been previous studies on classroom access control using smart cameras [27] and NFC [28].

Most of this previous research were performed independently, all focusing on how the attendance system works, the user behavior, and technology used. This research proposes the combination of the attendance system at the campus and smart classroom access by building an integrated system that can also access a classroom. It involves the use of fingerprint-scanning in the attendee process and management of attendee data with the classroom information system. Furthermore, the fingerprint data can also be used to authenticate access in the smart classroom.

\section{PROPOSED ATTENDANCE SYSTEM}

Contrary to [11]-[17] which were mainly focused on obtaining the attendee data list, the function of this attendance system also encompasses door security control and attendance recording for students and lecturers. It consists of identification, verification, and authentication processes. The door security control function involves unlocking and locking the door with a fingerprint access owned by the lecturer. Furthermore, the information system is adjusted according to the classroom's lecture schedule. The attendance recording function performs a scan of students' fingerprints and enters it into an attendance list database and then displays the report in the information system, as shown in Figure 1. The attendance process in the finite state machine (FSM) is shown in Figure 2.

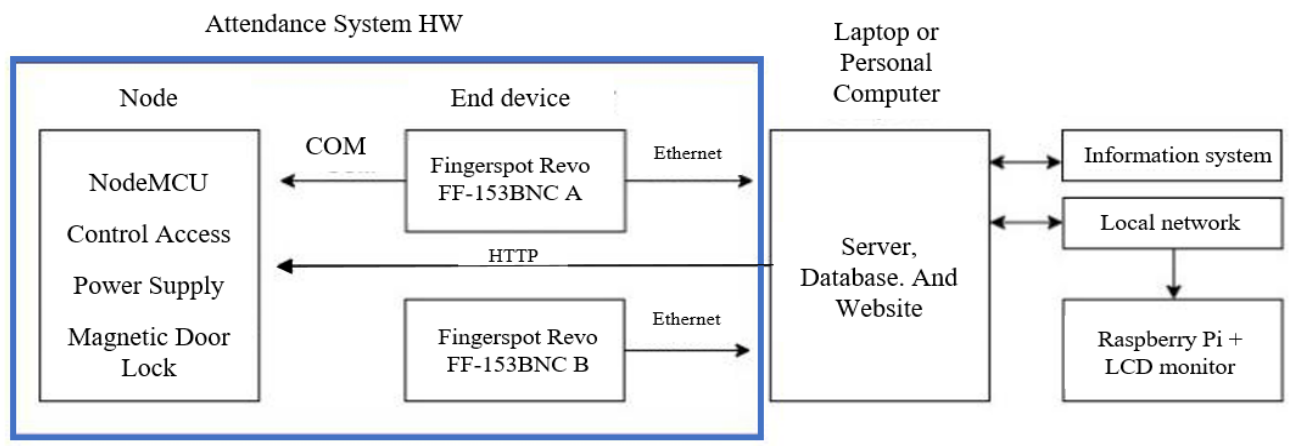

Figure 1. Smart classroom attendance system

The attendance system implementation begins by ascertaining the required components and connecting them each. The NodeMCU has an expansion board which enhances the connection accessibility between components. This system works because the lecturer scans their fingerprint on a scanning device installed outside the classroom before lecturing. When the lecturer's schedule and ID match, the classroom door then grants access. Furthermore, students sign their presence later on a fingerprint scan tool installed inside the classroom. As shown in Figure 3, this system consists of fingerspot revo FF-153BNC as the fingerprint scanning device, KitaServer application as the application forwarding scanning data to the server/database, NodeMCU as the central controller of classroom security, magnetic door lock as the door key, and a $12 \mathrm{~V}$ power supply for the magnetic lock.

The scanning device is connected to the KitaServer application to send the scanning fingerprint data to the ethernet database, while the NodeMCU uses Wi-Fi to communicate with the server. When the fingerprint device obtains the student's fingerprint, it directly authenticates the data and sends it to the server. The device also inputs the data in NodeMCU, where the authorization is performed by matching the scanning data with the lecturer's ID in the database. It checks whether the lecturer's ID matches the current schedule. When the authorization succeeds, NodeMCU then sends the signal to the magnetic door lock to grant access.

As shown in Figure 2, the first state of the door is closed. If the fingerprint is detected, it authenticates the lecture fingerprint. The lecture fingerprint triggered the next state. When the authentication success, it checks the schedule database and activates the class. While the door open, the student can enter the classroom and do their fingerprint scan as the attendance process on the class they entered. All the student's fingerprint data then saved in the database 


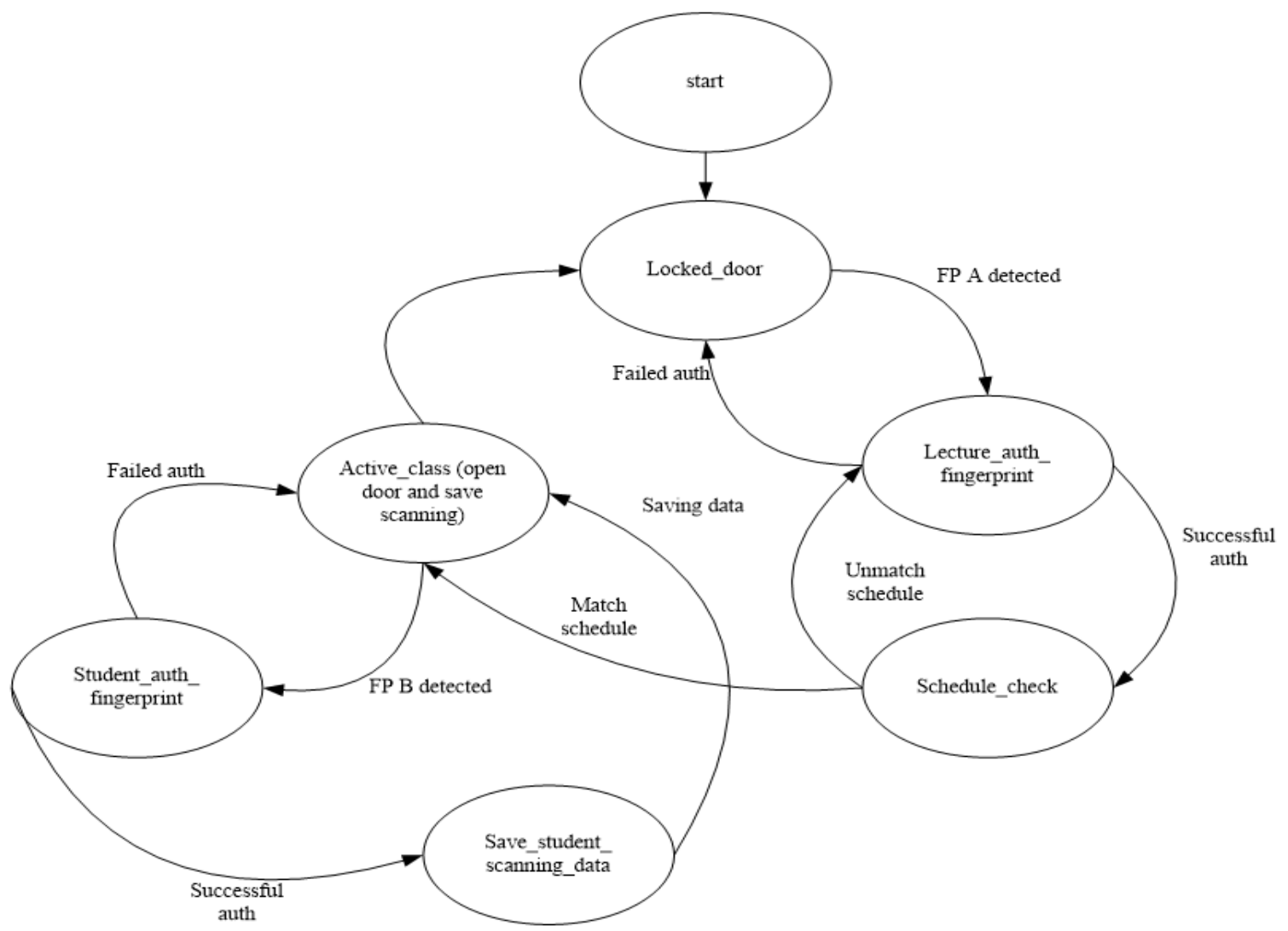

Figure 2. Attendance system in the finite state machine

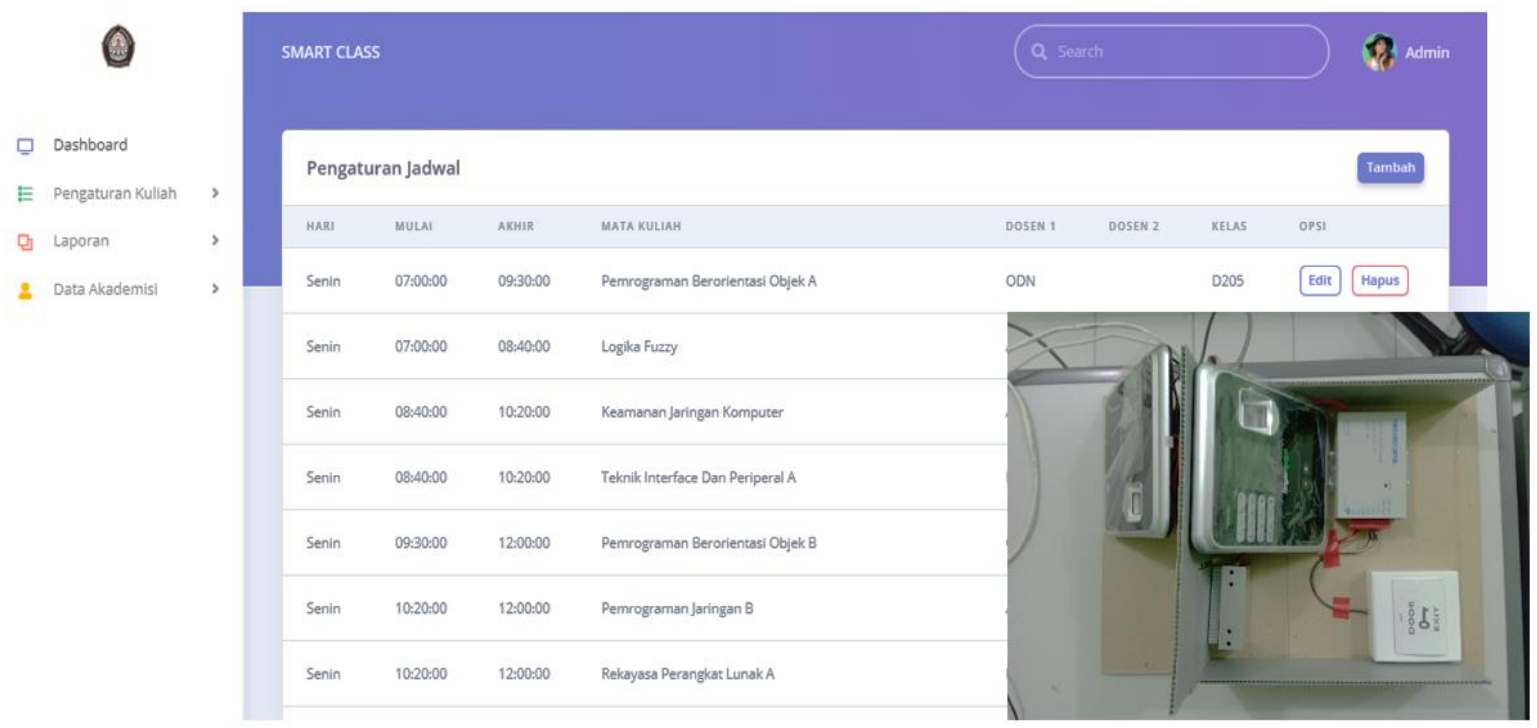

Figure 3. Attendance system implementation

\section{RESULTS AND ANALYSIS}

The testing mechanism was performed in two steps. The first was component testing which involved checking the technical function of each component before integration into one system. The second step involved checking the input-output component and communication structure. The system testing ascertains whether each component integrated into the system can work as specified. 


\subsection{Revo FF-153BNC fingerprint testing}

The revo FF-153BNC was used in the input component as a scanning device and door access. The testing was carried out by scanning ten registered users and one unregistered user to the system continuously for ten times with a 1-minute pause duration, as shown in Table 1. The result showed that Revo FF-153BNC identified user fingerprints with a $95 \%$ average. The possible reason for the unidentified scanning process was the user's sweat because the testing mechanism was done continuously for all users at the given time. Furthermore, classroom authorization testing also involves matching the lecturer's ID with the given schedule of the classroom, as shown in Table 2. This test done to ensure that only registered people were identified in the system.

The result showed that the authorization process on revo FF-153BNC based on the applied schedule is working correctly. The system successfully authorized the lecture scheduled for the class. This test is used to ensure that the lecturer who accesses the class is the one who has a schedule for that class.

Table 1. Result of Revo FF-153BNC fingerprint testing

\begin{tabular}{cccc}
\hline Testing & User & Identified scanning & Note \\
\hline 1 & User 1 & 10 & $100 \%$ identified \\
2 & User 2 & 10 & $100 \%$ identified \\
3 & User 3 & 10 & $100 \%$ identified \\
4 & User 4 & 10 & $100 \%$ identified \\
5 & User 5 & 10 & $100 \%$ identified \\
6 & User 6 & 10 & $100 \%$ identified \\
7 & User 7 & 10 & $100 \%$ identified \\
8 & User 8 & 10 & $100 \%$ identified \\
9 & User 9 & 9 & $90 \%$ identified \\
10 & User 10 & 8 & $80 \%$ identified \\
11 & Unregistered user & 0 & unidentified \\
\hline
\end{tabular}

Table 2. Classroom authorization testing

\begin{tabular}{ccccc}
\hline Testing & Class A & Class B & Class A Result & Class B Result \\
\hline 1 & Lecturer A & Lecturer B & Successful authorization & Successful authorization \\
2 & Lecturer A & Lecturer B & Successful authorization & Successful authorization \\
3 & Lecturer A & Lecturer B & Successful authorization & Successful authorization \\
4 & Lecturer A & Lecturer B & Successful authorization & Successful authorization \\
5 & Lecturer A & Lecturer B & Successful authorization & Successful authorization \\
6 & Lecturer B & Lecturer A & Failed authorization & Failed authorization \\
7 & Lecturer B & Lecturer A & Failed authorization & Failed authorization \\
8 & Lecturer B & Lecturer A & Failed authorization & Failed authorization \\
9 & Lecturer B & Lecturer A & Failed authorization & Failed authorization \\
10 & Lecturer B & Lecturer A & Failed authorization & Failed authorization \\
\hline
\end{tabular}

\subsection{Magnetic door lock testing}

This testing aims to ensure the output component works properly before integration into the system. Therefore, it involved sending input to the output component. Input high is provided to activate the magnetic door lock, while Input low was given to deactivate the lock. The testing result is shown in Figures 4 (a) and (b). Therefore, under normal circumstances the magnetic door lock was shown to work properly.

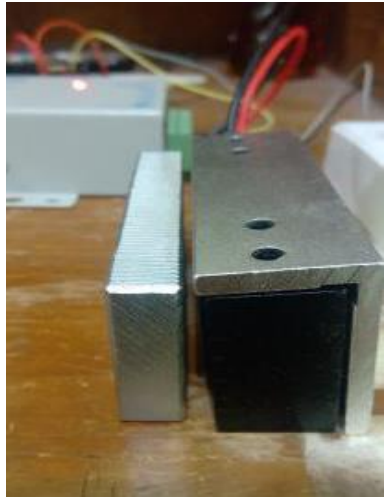

(a)

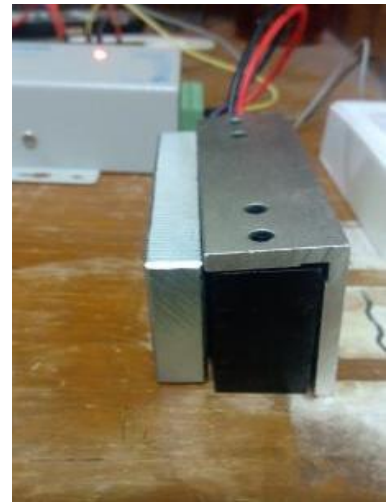

(b)

Figure 4. These Figures are; (a) magnetic door lock with low input and (b) magnetic door lock with high input

\footnotetext{
Internet of things based attendance system design and development in a smart classroom (Dania Eridani)
} 


\subsection{Communication testing}

The communication testing was carried out by checking the system's connection and data from the database's scanning device. This was performed by the NodeMCU which utilized a Wi-Fi connection. The distance capability of the NodeMCU connected with the access point was tested for every one meter. This testing only paid attention to the distance and not the obstacle between the distances. The result of the connection testing is shown in Table 3.

Table 3. Connection testing

\begin{tabular}{ccl}
\hline Testing & Distance $(\mathrm{m})$ & \multicolumn{1}{c}{ Connection } \\
\hline 1 & 1 & Connected \\
2 & 2 & Connected \\
3 & 3 & Connected \\
4 & 4 & Connected \\
5 & 5 & Connected \\
6 & 6 & Connected \\
7 & 7 & Connected \\
8 & 8 & Connected \\
9 & 9 & Connected \\
10 & 10 & Connected \\
11 & 11 & Connected, not stable \\
12 & 12 & Connected, not stable \\
13 & 13 & Connceted, not stable \\
14 & 14 & Unconnected \\
15 & 15 & Unconnected \\
\hline
\end{tabular}

Therefore, the NodeMCU best use is within a $10 \mathrm{~m}$ range using a Wi-Fi connection. The second part of communication testing involved checking the scanning device and database through Ethernet. The testing was done by recording the log of the user scanning process ten times on the "att_log" table in the fingerprint database. This "att_log" table is used to manage the information system. Figure 5 shows the "att_log" table result. The results showed that all recorded data can be stored on the database using an Ethernet connection.

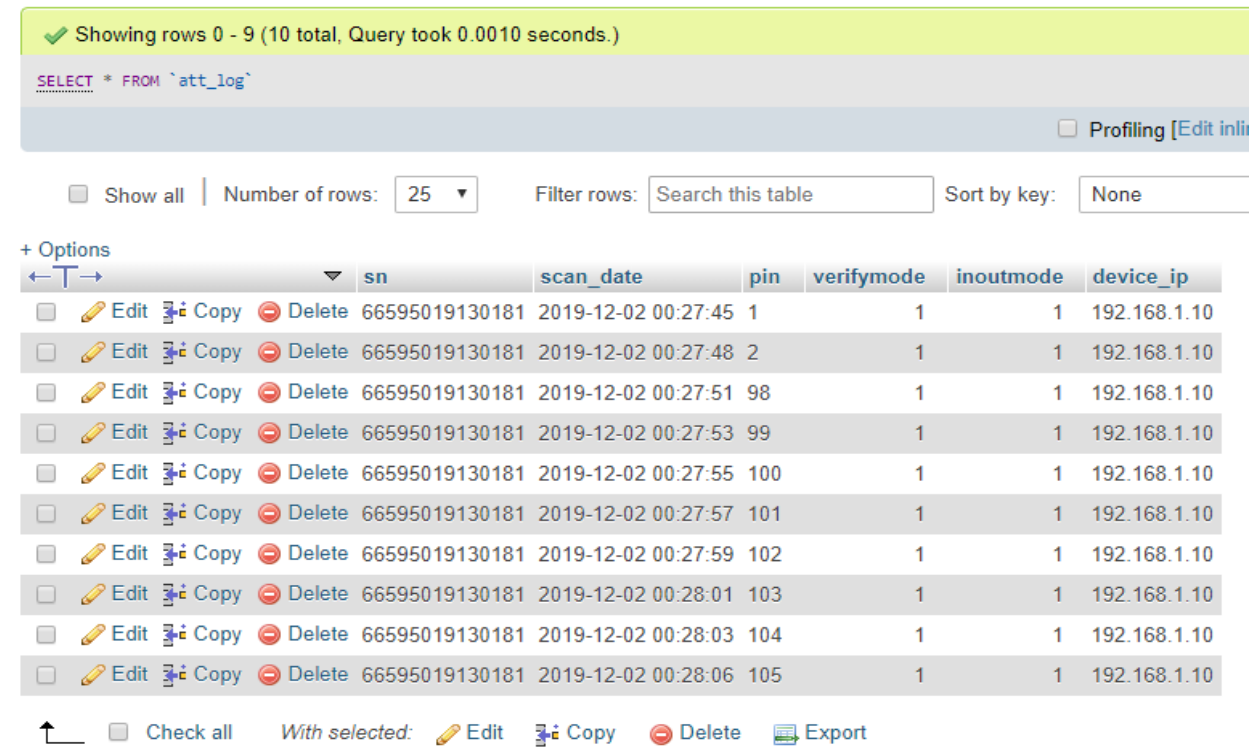

Figure 5. "Att_log" table result

\subsection{System testing}

Each component used in the system was integrated into the attendance system, and the functionality was then tested. The results are shown in Table 4. The system testing results showed that all of the attendance systems functions are working as specified. It is showed that the system could record all the attendance data by the lecture and the student as the schedule given. It also showed that the attendance system successfully integrated into the classroom security, as only users who have access can enter the classroom. 
Table 4. System testing

\begin{tabular}{clc}
\hline Testing & \multicolumn{1}{c}{ Parameter } & Result \\
\hline 1 & The ability to read fingerprints from Fingerspot Revo FF-154BNC & Success \\
2 & The ability to identify user fingerprints registered on the Fingerspot Revo FF-154BNC & Success \\
3 & The ability to save the fingerprint scan log to the database & Success \\
4 & The ability to authorize the scan log with the schedule given by the database & Success \\
5 & The ability to connect to Wi-Fi & Success \\
6 & The ability to unlock the magnetic door on completion of the authorization process & Success \\
\hline
\end{tabular}

\section{CONCLUSION}

The attendance system involving the IoT concept in this research was successfully tested and integrated with the security and classroom management system. The fingerprint of students and the lecturers were saved in the database, and the scanning device was able to send a script containing lecturer data to open the magnetic door lock in the classroom, which was dependent on the lecturer's schedule from the information system. Furthermore, the information system was able to display and manage attendance data based on fingerprint-scan process. The fingerspot revo FF-153BNC showed high accuracy in scanning data, and the longest connectivity which can be used between the NodeMCU, and the access point was 10 meters.

\section{ACKNOWLEDGEMENTS}

This research was supported by the Ministry of Research and Higher Education Indonesia with contract number 101-37/UN7.P4.3/PP/2019.

\section{REFERENCES}

[1] D. Heyne, "Developments in Classification, Identification, and Intervention for School Refusal and Other Attendance Problems: Introduction to the Special Series," Cognitive and Behavioral Practice, vol. 26, no. 1, pp. 1-7, 2019, doi: 10.1016/j.cbpra.2018.12.003.

[2] R. Banerjee, E. M. King, P. F. Orazem, and E. M. Paterno, "Student and teacher attendance: The role of shared goods in reducing absenteeism," Econ. Educ. Rev., vol. 31, no. 5, pp. 563-574, 2012.

[3] J. Cilliers, I. Kasirye, C. Leaver, P. Serneels, and A. Zeitlin, "Pay for locally monitored performance? A welfare analysis for teacher attendance in Ugandan primary schools," Journal of Public Economics, vol. 167, pp. 69-90, 2018, doi: 10.1016/j.jpubeco.2018.04.010.

[4] A. Lukkarinen, P. Koivukangas, and T. Seppälä, "Relationship between Class Attendance and Student Performance," Procedia - Soc. Behav. Sci., vol. 228, pp. 341-347, 2016, doi: 10.1016/j.sbspro.2016.07.051.

[5] R. Idei, H. Kato, and S. Morikawa, "Contribution of rural roads improvement on children's school attendance: Evidence in Cambodia," International Journal of Educational Development, vol. 72, p. 102131, 2020, doi: 10.1016/j.ijedudev.2019.102131.

[6] M. A. Nugroho and M. Andryzal Fajar, "Effects of Technology Readiness Towards Acceptance of Mandatory Web-Based Attendance System," Procedia Computer Science, vol. 124, pp. 319-328, 2017, doi: 10.1016/j.procs.2017.12.161.

[7] H. D. Rjeib, N. S. Ali, A. Al Farawn, and B. Al-sadawi, "Attendance and Information System using RFID and Web-Based Application for Academic Sector," International Journal of Advanced Computer Science and Applications, vol. 9, no. 1, pp. 266-274, 2018, doi: 10.14569/IJACSA.2018.090137.

[8] K. R. Pireva, J. Siqeca, and S. Berisha, "RFID: Management system for students' attendance," IFAC Proceedings Volumes, vol. 46, no. 8, 2013, pp. 137-140, doi: 10.3182/20130606-3-XK-4037.00057.

[9] Q. Miao, F. Xiao, H. Huang, L. Sun, and R. Wang, "Smart attendance system based on frequency distribution algorithm with passive RFID tags," in Tsinghua Science and Technology, vol. 25, no. 2, pp. 217-226, April 2020, doi: 10.26599/TST.2018.9010141.

[10] S. Hameed, S. M. T. Saquib, M. ul Hassan, and F. Junejo, "Radio Frequency Identification (RFID) Based Attendance \& Assessment System with Wireless Database Records," Procedia - Soc. Behav. Sci., vol. 195, pp. 2889-2895, 2015, doi: 10.1016/j.sbspro.2015.06.414.

[11] D. Shah and V. Bharadi, "IoT based Biometrics Implementation on Raspberry Pi," Procedia Computer Science, vol. 79, pp. 328-336, 2016, doi: 10.1016/j.procs.2016.03.043.

[12] G. Sittampalam and N. Ratnarajah, "SAMS: An IoT Solution for Attendance Management in Universities," TENCON 2019 - 2019 IEEE Region 10 Conference (TENCON), 2019, pp. 251-256, doi: 10.1109/TENCON.2019.8929616.

[13] C. O. Sogbaike and V. O. Ahoro, "Design And Implementation Of Class Attendance Management System Using Fingerprint Recognition," International Journal of Scientific and Research Publications, vol. 9, no. 5, pp. 882-897, 2019, doi: 10.29322/IJSRP.9.05.2019.p89110.

[14] L. S. Ezema, J. N. Eneh, and I. Amanze, "Fingerprint-Based-Attendance-Management-System," International Journal of Scientific \& Engineering Research, vol. 6, no. 7, pp. 1623-1628, 2015. 
[15] K. Krishnamurthi, S. I. Mary, B. N. Sumalatha, and A. Pereira, "Fingerprint Based Attendance System," International Journal of Advanced Research in Computer and Communication Engineering, vol. 4, no. 3, pp. 621-623, 2015, doi: 10.17148/IJARCCE.2015.43149.

[16] R. P. J, R. Pavithra, N. Aswini, and F. B. A, "Wireless Smart Biometric Attendance System,” International Journal of Innovative Technology and Exploring Engineering, vol. 8, no. 2S, pp. 156-159, 2018.

[17] N. Prince, A. Sengupta, and M. K. Unni, "Implementation of IoT Based Attendance System on a Dedicated WebServer," International Journal of Scientific \& Engineering Research, vol. 7, no. 6, pp. 351-355, 2016.

[18] S. M. Bah and F. Ming, "An improved face recognition algorithm and its application in attendance management system," Array, vol. 5, pp. 100014, 2020, doi: 10.1016/j.array.2019.100014.

[19] J. Vamsikrishna, K. Anudeep, L. J. A. Marcilin, and V. Balamurugan, "An Advanced Attendance Marking system using facial Recognition," IOP Conference Series: Materials Science and Engineering, vol. 590, 2019, doi: 10.1088/1757-899X/590/1/012049.

[20] D. Sunaryono, J. Siswantoro, and R. Anggoro, "An android based course attendance system using face recognition," Journal of King Saud University - Computer and Information Sciences, vol. 33, no. 3, pp. 304-312, 2019, doi: 10.1016/j.jksuci.2019.01.006.

[21] Y. S. V. Lakshmi and V. J. Kumar, "Smart Biometric Attendance and Monitoring System," International Journal of Computer Sciences and Engineering, vol. 7, no. 6, pp. 901-905, 2019, doi: 10.26438/ijcse/v7i6.901905.

[22] K. Mohammed, A. S. Tolba, and M. Elmogy, "Multimodal student attendance management system ( MSAMS )," Ain Shams Engineering Journal, vol. 9, no. 4, pp. 2917-2929, 2018, doi: 10.1016/j.asej.2018.08.002.

[23] A. Ademola, T. E. Somefun, A. F. Agbetuyi, and A. Olufayo, "Web based fingerprint roll call attendance management system," International Journal of Electrical and Computer Engineering (IJECE), vol. 9, no. 5, pp. 4364-4371, 2019, doi: 10.11591/ijece.v9i5.pp4364-4371.

[24] L. Huang, J. Su, and T. Pao "A Context Aware Smart Classroom Architecture for Smart Campuses," Applied Sciences, vol. 9, no. 9, 2019, doi: 10.3390/app9091837.

[25] M. Patted, S. Muley, and D. Panda, "Intelligent Classroom Automation System using PIC Microcontroller," International Journal of Research in Engineering and Technology, vol. 5, no. 6, pp. 154-160, 2016.

[26] Pratibha, B. V. Pallavi, and B. Gadgay, "Smart Classroom using Raspberry pi," Int. J. Res. Appl. Sci. Eng. Technol., vol. 6, no. 7, pp. 467-470, 2018, doi: 10.22214/ijraset.2018.7067.

[27] J. Yang, C. Lai, H. Sheu, and J. Chen, "An Intelligent Automated Door Control System Based on a Smart Camera," vol. 13, no. 5, pp. 5923-5936, 2013, doi: 10.3390/s130505923.

[28] D. Palma, J. E. Agudo, H. Sánchez, and M. M. Macías, "An internet of things example: Classrooms access control over near field communication," Sensors (Switzerland), vol. 14, no. 4, pp. 6998-7012, 2014, doi: 10.3390/s140406998.

\section{BIOGRAPHIES OF AUTHORS}

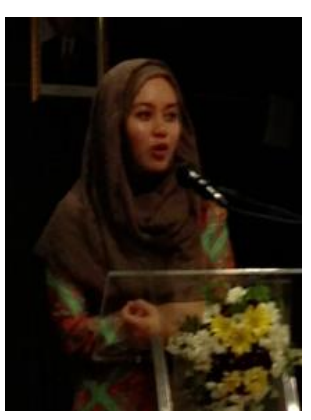

Dania Eridani pursued Bachelor Degree in Electrical Engineering from Diponegoro University and Master Degree in Electrical Engineering from Gadjah Mada University. She is currently working as Instructor at Department of Computer Engineering Diponegoro University. Her main research focuses on Computer Engineering, Embedded System, IoT implementation, and Human Computer Interaction. She has 6 years of teaching and research experience.

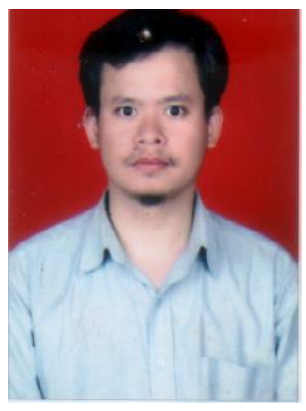

Eko Didik Widianto pursued Bachelor Degree and Master Degree in Electrical Engineering from Bandung Institute of Technology. He is currently working as Assistant Professor at Department of Computer Engineering Diponegoro University. His main research focuses on Computer Engineering, Embedded System, IoT implementation, Microelectronics, Wireless Sensor Network, Distributed System, and Cyber Security. He has 4 years industrial working experience, 10 years teaching experience, and 19 years research experience. 


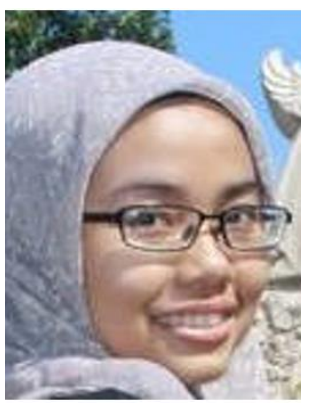

Ike Pertiwi Windasari pursued Bachelor Degree in Electrical Engineering from Diponegoro University and Master Degree in Informatic Engineering from Bandung Institute of Technology. Her main research focused on Software Engineering and Big Data. She has 10 years teaching and research experience.

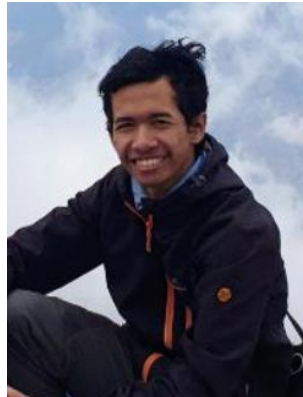

Wildan Budi Bawono pursued Bachelor Degree in Computer Engineering Diponegoro University. He is been part of this research for 1 years.

Nadia Febrianita Gunarto pursued Bachelor Degree in Computer Engineering Diponegoro University. He is been part of this research for 1 years.

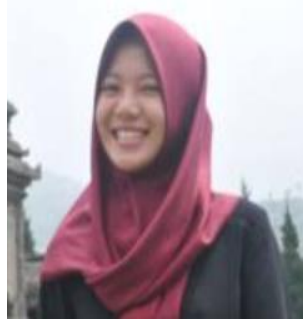

